Chronic Obstructive Pulmonary Diseases: Journal of the COPD Foundation

\author{
Original Research
}

\title{
The 2014 Updated GOLD Strategy: A Comparison of the Various Scenarios
}

Sarah Wilke, MSc, ${ }^{* 1}$ Dionne E. Smid, MSc, ${ }^{* 1}$ Martijn A. Spruit, PhD, ${ }^{1}$ Daisy J. A. Janssen, MD, PhD, ${ }^{1,2}$ Jean W. M. Muris, MD, PhD, ${ }^{3}$ Thys van der Molen, MD, PhD, ${ }^{4}$ Marjan van den Akker, PhD, ${ }^{3,5}$ Paul W. Jones, MD, PhD, ${ }^{6}$ Emiel F.M. Wouters, MD, PhD, ${ }^{1,7}$ and Frits M.E. Franssen, $\mathrm{MD}, \mathrm{PhD}^{1}$

* Joint first author

\section{Abstract}

Background: The 2014 updated Global initiative for chronic Obstructive Lung Disease (GOLD) strategy added the St. George's Respiratory Questionnaire (SGRQ) as the fourth possible symptoms measure. The impact of the suggested tools for symptoms of COPD and the different definitions of future risk on the frequency distribution and clinical characteristics of the GOLD groups remain unknown.

Methods: Demographic and clinical characteristics were assessed in 542 patients with COPD (57.7\% male, age 64.6 [9.0] years, $\mathrm{FEV}_{1} 54.7$ [22.3]\% predicted). Health status was assessed by the COPD-specific SGRQ and symptoms of anxiety and depression by the Hospital Anxiety and Depression Scale, anxiety (HADS-A) and depression (HADS-D) subscale. Cohen's Kappa was used to assess agreement between groups.

Results: Level of agreement in frequency distribution using the modified Medical Research Council dyspnea ( $\mathrm{mMRC}$ ) scale $\geq 2$, COPD Assessment Test (CAT) $\geq 10$, Clinical COPD Questionnaire (CCQ) $\geq 1$ and SGRQ $\geq 25$ was moderate to very good. Best agreement was reached between CCQ and SGRQ ( $K=0.838$ or $0.851, p<0.001)$. Patients classified in mMRC GOLD A reported higher SGRQ scores, higher HADS-A and HADS-D scores compared to patients classified in CAT GOLD A or SGRQ GOLD A. Outcomes were comparable between the risk assessment groups.

Conclusions: Choice of the symptom measure impacts GOLD groups more than choice of the exacerbation risk assessment. Health care professionals should be aware that patients are heterogeneous in terms of health status and symptoms of anxiety and depression based on the symptom measure used.

\begin{abstract}
Abbreviations: Global initiative for chronic Obstructive Lung Disease, GOLD; St. George's Respiratory Questionnaire, SGRQ; Hospital Anxiety and Depression Scale, anxiety subscale, HADS-A; Hospital Anxiety and Depression Scale, depression subscale, HADS-D; COPD Assessment Test, CAT; Clinical COPD Questionnaire, CCQ; modified Medical Research Council dyspnea scale, mMRC; body mass index, BMI; forced expiratory volume in 1 second, FEV $_{1}$; forced vital capacity, FVC; Timed Up and Go test, TUG test; COPD-specific version of St. George's Respiratory Questionaire, SGRQ-C; least significance difference, LSD.

Funding Support: This study was financially supported by the Lung Foundation Netherlands (3.4.10.015) and GlaxoSmithKline (SCO115406). Date of Acceptance: July 9, 2014

Citation: Wilke S, Smid DE, Spruit MA, et al. The 2014 updated GOLD strategy: A comparison of the various scenarios. J COPD F. 2014; 212-220. doi: http://dx.doi.org/10.15326/jcopdf.1.2.2014.0135
\end{abstract}

\section{This article has an online supplement.}

1 Department of Research \& Education, CIRO+, Centre of Expertise for Chronic Organ Failure, Horn, the Netherlands

2 Centre of Expertise for Palliative Care, Maastricht University Medical Centre, the Netherlands

3 Caphri School of Public Health and Primary Care, Department of Family Medicine, Maastricht University, the Netherlands
4 Department of General Practice, University of Groningen, University Medical Centre Groningen, the Netherlands

5 Department of General Practice, KU Leuven, Leuven, Belgium

6 Division of Clinical Science, St. George's University of London, United Kingdom

7 Department of Respiratory Medicine, Maastricht University Medical Centre, the Netherlands 


\section{Address correspondence to:}

\section{Sarah Wilke, MSc}

Department of Research \& Education

CIRO+, Centre of Expertise for Chronic Organ Failure

Hornerheide 1, 6085 NM Horn, the Netherlands

Telephone: +31 (0)475 587603

E-mail: sarahwilke@ciro-horn.nl

\section{Keywords:}

chronic obstructive pulmonary disease; COPD; COPD

Assessment Test; CAT; clinical COPD questionnaire; CCQ; St. George's Respiratory Questionnaire; SGRQ; Global initiative for chronic Obstructive Lung Disease; GOLD;

\section{Introduction}

The 2007 Global initiative for chronic Obstructive Lung Disease (GOLD) statement classified COPD patients into 4 groups (GOLD stages I to IV), based on the degree of airflow limitation. ${ }^{1}$ This parameter, however, is only poorly-to-moderately associated with disease activity and progression, extra-pulmonary features and comorbidities, and prognosis in COPD patients. ${ }^{2-4}$ Therefore, the 2011 GOLD strategy started classifying patients in 4 new groups (GOLD groups $A$ to D) based on the combination of the degree of airflow limitation and the number of exacerbations in the past 12 months (A/B vs. C/D); and the severity of symptoms (A/C vs. $\mathrm{B} / \mathrm{D}$ ) (Table 1). To assess the severity of symptoms, the GOLD strategy recommends new, simple and reliable assessment tools, designed for use in routine daily clinical practice. ${ }^{5}$

Jones and colleagues ${ }^{6}$ were the first to study the impact of the choice of symptom measure (modified

\section{Table 1. Overview of GOLD Strategies}

\begin{tabular}{|c|c|c|c|c|c|}
\hline & & I & II & III & IV \\
\hline \multirow[t]{2}{*}{$\begin{array}{l}\text { GOLD } \\
2007\end{array}$} & & $\mathrm{FEV}_{1} \geq 80 \%$ pred & $\begin{array}{l}\mathrm{FEV}_{1} \geq 50 \% \text { pred } \\
<80 \% \text { pred }\end{array}$ & $\begin{array}{l}\text { FEV } 1 \geq 30 \% \text { pred } \\
<50 \% \text { pred }\end{array}$ & FEV $1<30 \%$ pred \\
\hline & & $\mathbf{A}$ & B & C & D \\
\hline \multirow[t]{2}{*}{$\begin{array}{l}\text { GOLD } \\
2011\end{array}$} & $\begin{array}{l}\text { GOLD } 2007 \text { or } \\
\text { Exacerbation history }^{\mathrm{a}}\end{array}$ & $\begin{array}{l}\text { GOLD I or II } \\
0-1 \text { exacerbations }\end{array}$ & $\begin{array}{l}\text { GOLD I or II } \\
0-1 \text { exacerbations }\end{array}$ & $\begin{array}{l}\text { GOLD III or IV } \\
\geq 2 \text { exacerbations }\end{array}$ & $\begin{array}{l}\text { GOLD III or IV } \\
\geq 2 \text { exacerbations }\end{array}$ \\
\hline & $\begin{array}{l}\text { mMRC grade } \\
\text { CAT, points }\end{array}$ & $\begin{array}{l}0-1 \\
<10\end{array}$ & $\begin{array}{l}\geq 2 \\
\geq 10\end{array}$ & $\begin{array}{l}0-1 \\
<10\end{array}$ & $\begin{array}{l}\geq 2 \\
\geq 10\end{array}$ \\
\hline \multirow[t]{5}{*}{$\begin{array}{l}\text { GOLD } \\
2013\end{array}$} & $\begin{array}{l}\text { GOLD } 2007 \text { or } \\
\text { Exacerbation history }^{\mathrm{a}}\end{array}$ & $\begin{array}{l}\text { GOLD I or II } \\
\text { 0-1 exacerbations }\end{array}$ & $\begin{array}{l}\text { GOLD I or II } \\
\text { 0-1 exacerbations }\end{array}$ & $\begin{array}{l}\text { GOLD III or IV } \\
\geq 2 \text { exacerbations }\end{array}$ & $\begin{array}{l}\text { GOLD III or IV } \\
\geq 2 \text { exacerbations }\end{array}$ \\
\hline & $\begin{array}{l}\text { GOLD } 2007 \text { or } \\
\text { Hospitalization historya }\end{array}$ & $\begin{array}{l}\text { GOLD I or II } \\
\text { No hospitalizations }\end{array}$ & $\begin{array}{l}\text { GOLD I or II } \\
\text { No hospitalizations }\end{array}$ & $\begin{array}{l}\text { GOLD III or IV } \\
\geq 1 \text { hospitalization }\end{array}$ & $\begin{array}{l}\text { GOLD III or IV } \\
\geq 1 \text { hospitalization }\end{array}$ \\
\hline & mMRC grade or & $0-1$ & $\geq 2$ & $0-1$ & $\geq 2$ \\
\hline & CAT, points or & $<10$ & $\geq 10$ & $<10$ & $\geq 10$ \\
\hline & CCQ, points & $<1$ & $\geq 1$ & $<1$ & $\geq 1$ \\
\hline
\end{tabular}

\begin{tabular}{llllll} 
GOLD & GOLD 2007 or & GOLD I or II & GOLD I or II & GOLD III or IV & GOLD III or IV \\
2014 & Exacerbation history $^{2}$ & O-1 exacerbations & O-1 exacerbations & $\geq 2$ exacerbations & $\geq 2$ exacerbations \\
\cline { 2 - 5 } & GOLD 2007 or & GOLD I or II & GOLD I or II & GOLD III or IV & GOLD III or IV \\
Hospitalization historya & No hospitalizations & No hospitalizations & $\geq 1$ hospitalization & $\geq 1$ hospitalization \\
\hline mMRC grade or & $0-1$ & $\geq 2$ & $0-1$ & $\geq 2$ \\
CAT, points or & $<10$ & $\geq 10$ & $<10$ & $\geq 10$ \\
CCQ, points or & $<1.0-1.5$ & $\geq 1.0-1.5$ & $<1.0-1.5$ & $\geq 1.0-1.5$ \\
SGRQ, points & $<25$ & $\geq 25$ & $<25$ & $\geq 25$
\end{tabular}

\footnotetext{
${ }^{a}$ If there is a discrepancy between the risk group as classified by airflow limitation or exacerbation/hospitalization history, the GOLD strategy suggests to use the parameter with worst future risk.
} 
Medical Research Council dyspnea [mMRC] scale or COPD Assessment Test [CAT]) on the frequency distribution and clinical characteristics of the GOLD groups. The current mMRC cut-point of grade $\geq 2$ did not match with the current CAT cut-point of $\geq 10$ points. ${ }^{6}$ Thus, the choice of symptom measure clearly influences the new GOLD classification, ${ }^{6,7}$ and in turn, the necessity for refinement of the current $\mathrm{mMRC}$ and/ or CAT cut-points was suggested.

The 2013 GOLD strategy added the Clinical COPD Questionnaire (CCQ) as the third possibility to classify patients to the low (A/C) or high (B/D) symptom group. Moreover, the number of COPD hospitalizations in the past 12 months (cut-point: $\geq 1$ hospitalizations) was added as the third criterion to classify patients as GOLD low (A/B) or high (C/D) risk. ${ }^{8}$ Casanova and colleagues ${ }^{9}$ showed that the symptom measure (i.e. mMRC, CAT or CCQ) used "can substantially alter group assignment.” Since the St. George's Respiratory Questionnaire (SGRQ) is the most documented measure and commonly used in COPD studies, the 2014 updated GOLD strategy added the SGRQ (cut-point: $\geq 25$ points) as a fourth possibility to grade symptoms. ${ }^{10}$ To date, the impact of all of these introduced assessment tools on the frequency distribution and clinical characteristics of the GOLD groups remain unknown. Therefore, the aims of the present study were: 1) to investigate the impact of the 4 different assessment tools for symptoms (mMRC, CAT, CCQ or SGRQ) and different definitions of future risk (degree of airflow limitation/ $\geq 2$ COPD exacerbations, and degree of airflow limitation $/ \geq 1$ hospitalization for COPD exacerbation) on the frequency distribution of GOLD groups A to D; and 2) to study differences in health status, functional mobility, symptoms of anxiety and depression, and self-reported comorbidities between the GOLD groups using these different scenarios. We hypothesized a priori that the symptom measures impact the GOLD distribution as well as the clinical characteristics of the GOLD groups.

\section{Methods}

\section{Design}

The current cross-sectional analyses are part of an ongoing prospective observational study about determinants of health status assessed with CAT in a broad sample of COPD patients. The Medical Ethical Committee of the Maastricht University Medical Centre+ Maastricht, the Netherlands (METC 11-3-070) approved this study, which was registered at the Dutch Trial Register (NTR 3416).

\section{Study Population}

Patients were eligible to participate if they had a primary diagnosis of COPD and if they were clinically stable for at least 4 weeks preceding enrollment. Patients were excluded if they had a history of other lung diseases, had undergone lung surgery or had a malignancy within the last 5 years. All patients gave written informed consent.

Patients were recruited in primary, secondary and tertiary care settings between April 2012 and April 2014. Primary care patients only received treatment by their general practitioner and never contacted a chest physician or were previously treated in tertiary care. Secondary care patients were only treated by a chest physician but were not previously treated in tertiary care. Primary and secondary care patients were recruited through general practitioner practices selected from the Registration Network of Family Practices, RNH. ${ }^{11}$ Tertiary care patients were recruited at $\mathrm{CIRO}+$, a center for pulmonary rehabilitation in Horn, the Netherlands, during their pre-rehabilitation assessment.

\section{Measurements}

Primary and secondary care patients were assessed during home visits, while tertiary care patients were measured during an inpatient pre-rehabilitation assessment. $^{12}$ Demographics, body mass index (BMI), smoking status, number of exacerbations and hospitalizations during the last 12 months, use of long-term oxygen therapy, current medication, post-bronchodilator spirometry (forced expiratory volume in 1 second, [FEV 1 , and forced vital capacity, [FVC]), mMRC dyspnea grade, ${ }^{13}$ functional mobility (Timed Up and Go [TUG] test) ${ }^{14}$ and self-reported comorbidities (Charlson Comorbidity Index) ${ }^{15}$ were assessed. Symptoms of anxiety and depression were assessed by using the Hospital Anxiety and Depression Scale, consisting of an anxiety subscale (HADS-A) and depression subscale (HADS-D). ${ }^{16,17}$ In addition, disease-specific health status was assessed using the $\mathrm{CAT}^{18}$ the $\mathrm{CCQ}^{19}$ and the COPD-specific version of the SGRQ (SGRQ-C). ${ }^{20}$ SGRQ scores were used to assess differences in health status between the various scenarios.

\section{Statistics}

Allocation to GOLD groups was made using mMRC 
$\geq 2$ vs. CAT $\geq 10$ or CCQ $\geq 1$ or $S G R Q \geq 25$ and degree of airflow limitation $/ \geq 2$ exacerbations vs. degree of airflow limitation $/ \geq 1$ hospitalization in the previous 12 months. Bivariate correlations (Pearson's productmoment correlation) between mMRC, CAT, CCQ and SGRQ scores were assessed. Cohen's Kappa was used to assess agreement between the frequencies of patients classified into GOLD groups $A$ to $D$ using the different cut-points. Kappa values were categorized as having poor (<0.0), slight (0.00-0.20), fair (0.21-0.40), moderate (0.41-0.60), substantial (0.61-0.80), and very good (0.81-1.00) agreement. ${ }^{21}$ Patient characteristics were compared between GOLD groups A to D using univariate analysis of variance for continuous variables, followed by post hoc least significance difference (LSD) multiple comparisons, or Kruskal-Wallis test followed by Mann-Whitney U test, as appropriate. Categorical variables were compared using ChiSquare tests. The same statistics were used to compare patient characteristics and health status, symptoms of anxiety and depression, the TUG test, and self-reported comorbidities between GOLD groups. For other tests, the independent sample t-test or Mann-Whitney $U$ test were used, as appropriate. All statistical analyses were performed using SPSS for Windows, Version 19.0. A $\mathrm{p}$-value $\leq 0.01$ was interpreted as statistically significant.

\section{Results}

\section{Patient Characteristics Figure 1. Frequency Distribution}

In total, 542 patients with moderate to very severe COPD were included. Characteristics of the study population are presented in Table 2.

\section{The Impact of Symptom Measure on Frequency Distribution}

The mMRC, CAT, and SGRQ scores were moderately to strongly correlated, with the best relationship being between the CCQ and SGRQ ( $\mathrm{r}=$ 0.853, $\mathrm{p}<0.001$ ) (e-Figure 1). Using the cut-points selected, the majority of the patients were classified

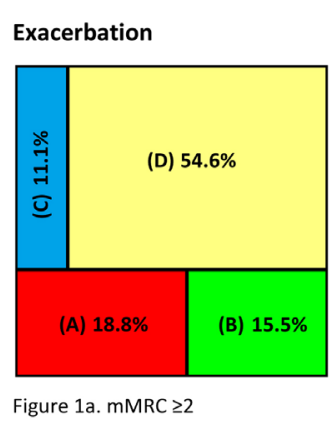

Hospitalization

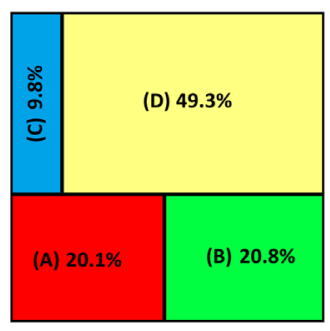

Figure 1e. $m M R C \geq 2$

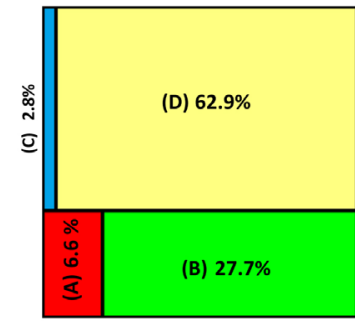

Figure 1b. CAT $\geq 10$

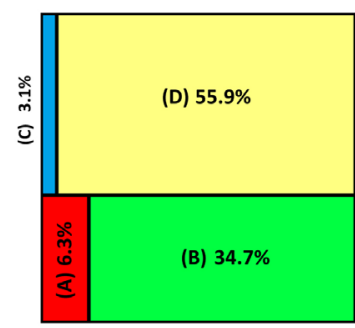

Figure 1f. CAT $\geq 10$

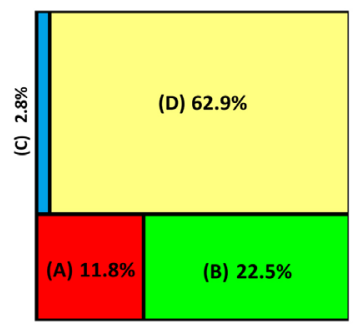

Figure 1c. $\mathrm{CCO} \geq 1$

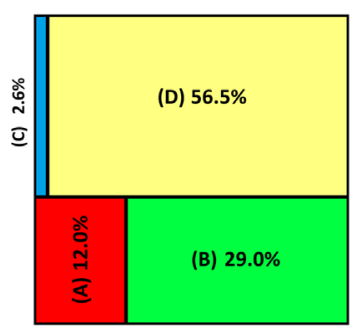

Figure 1g. $C C Q \geq 1$

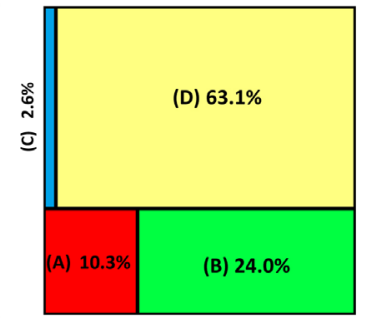

Figure 1d. SGRQ $\geq 25$

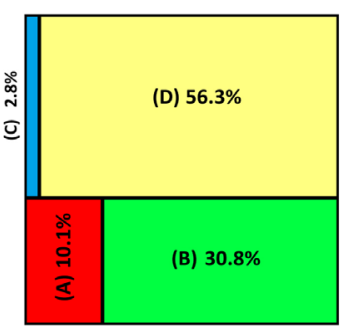

Figure 1 h. $S G R Q \geq 25$ as GOLD D, irrespective of the symptom measure used (Figure 1). The agreement of classification (Kappa 
Table 3. Cohen's Kappa Between Different Symptom Measures and Same Risk Assessments

\begin{tabular}{|c|c|c|c|}
\hline \multicolumn{4}{|c|}{ Degree of Airflow Limitation/Exacerbation History as Risk Assessment } \\
\hline & CAT & $\operatorname{cc} Q$ & SGRQ \\
\hline mMRC & 0.602 & 0.694 & 0.678 \\
\hline CAT & - & 0.806 & 0.787 \\
\hline $\mathrm{CCQ}$ & - & - & 0.838 \\
\hline \multicolumn{4}{|c|}{ Degree of Airflow Limitation/Hospitalization History as Risk Assessment } \\
\hline & CAT & CCQ & SGRQ \\
\hline mMRC & 0.626 & 0.712 & 0.698 \\
\hline CAT & - & 0.820 & 0.803 \\
\hline $\mathrm{CCQ}$ & - & - & 0.851 \\
\hline
\end{tabular}

values) into low (A/C) or high (B/D) symptom GOLD groups using the mMRC, CAT, CCQ or SGRQ scores is summarized in Table 3. There was a moderate to substantial agreement $(\mathrm{K}=0.602$ or $0.626, \mathrm{p}<0.001)$ between $\mathrm{mMRC}$ and CAT and very good agreement (K $=0.838$ or $0.851, \mathrm{p}<0.001$ ) between CCQ and SGRQ scores.

\section{The Impact of Symptom Measure on Clinical Characteristics}

On average, GOLD B/D patients had worse diseasespecific health status scores compared to GOLD A/C patients, with worst (=highest) health status scores in GOLD D groups (Figure 2, e-Table 1a and e-Table 1b). mMRC GOLD A patients had a significantly worse health status compared to CAT GOLD A, CCQ GOLD A and SGRQ GOLD A patients. mMRC GOLD B, CCQ GOLD B and SGRQ GOLD B patients reported significantly worse health status compared to CAT GOLD B patients. In GOLD C and D groups, however, mean SGRQ scores were comparable between the symptom measures mMRC, CAT and CCQ. MMRC GOLD $C$ and CAT GOLD $C$ patients reported worse health status compared to SGRQ GOLD $C$ patients (Figure 2). On average, GOLD B/D patients needed more time to complete the TUG test compared to GOLD A/C patients, with worst impairment in GOLD D patients. mMRC GOLD B patients and SGRQ GOLD $B$ patients reported more comorbidities compared to mMRC GOLD A, C and D patients and SGRQ A and D patients, respectively (e-Table $1 \mathrm{a}$ and e-Table $1 \mathrm{~b}$ ). There were no differences in the number of self-reported comorbidities and time needed to complete the TUG test between GOLD groups using mMRC, CAT, CCQ or SGRQ (Figure 2).

\section{Figure 2.}

\section{Clinical Characteristics Stratified by GOLD Groups}
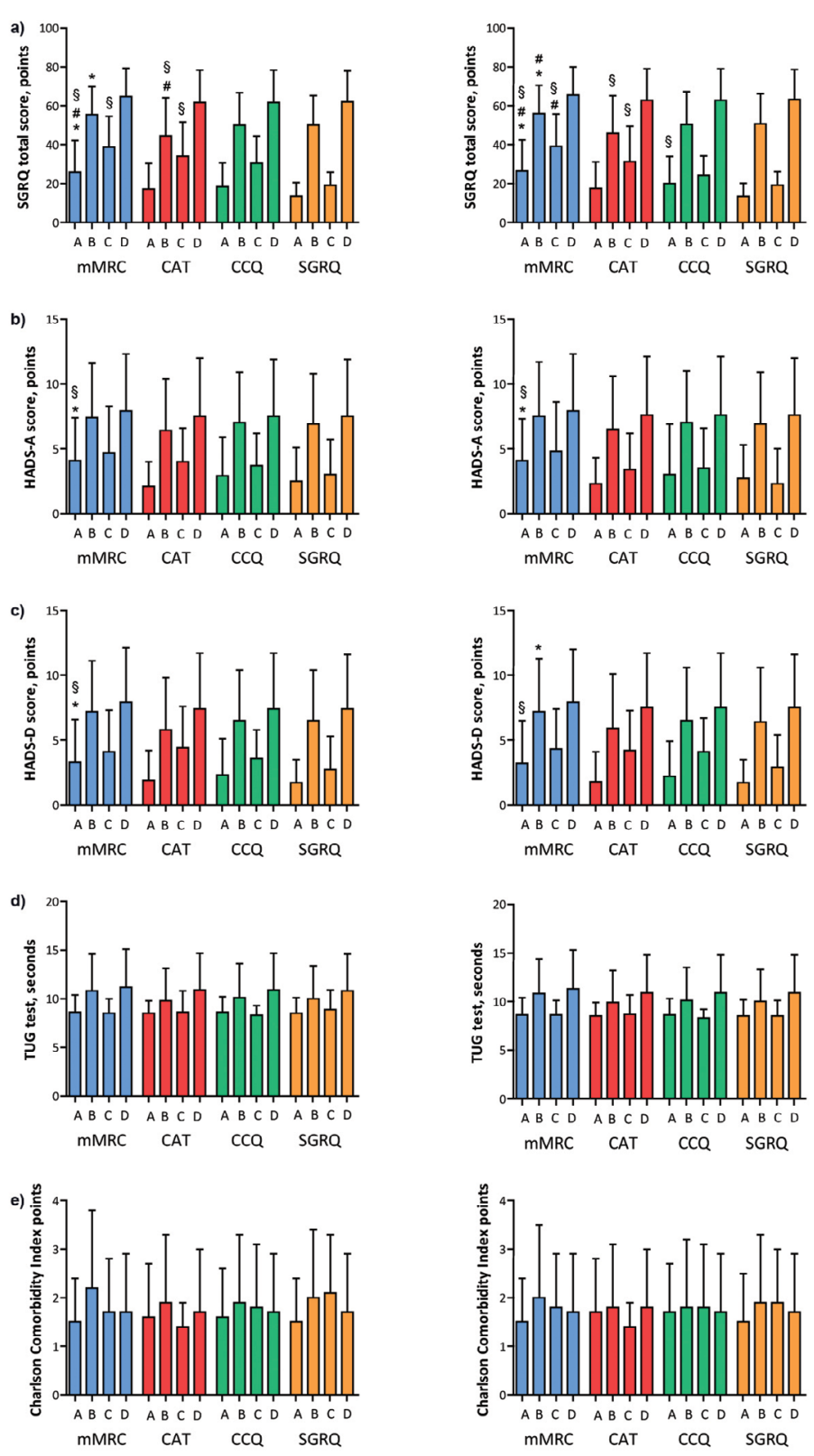

a) SGRQ, b) symptoms of anxiety (HADS-A) c) depression (HADS-D), d) functional mobility (TUG test) and e) self-reported comorbidities (Charlson Comorbidity Index) stratified by symptom measure and exacerbation risk assessment (left column: degree of airflow limitation/exacerbation history; right column: degree of airflow limitation/hospitalization history). Significances are only described for comparison between similar GOLD groups using different symptom measures (e.g. mMRC GOLD A vs. CAT GOLD A vs. CCQ GOLD A vs. SGRQ GOLD A. For significances within each symptom measure please see online supplementary e-Table 1a and e-Table 1b). " $\mathrm{p} \leq 0.01$ vs. CAT; ${ }^{*} \mathrm{p} \leq 0.01$ vs. CCQ; ${ }_{\mathrm{p}} \leq 0.01$ vs. SGRQ

On average, GOLD B/D patients reported significantly higher HADS-A and HADS-D scores compared to GOLD A/C patients (e-Table $1 \mathrm{a}$ and e-Table $1 \mathrm{~b}$ ). mMRC 
Table 4. Cohen's Kappa Between Different Risk Assessments and Same Symptom Measures

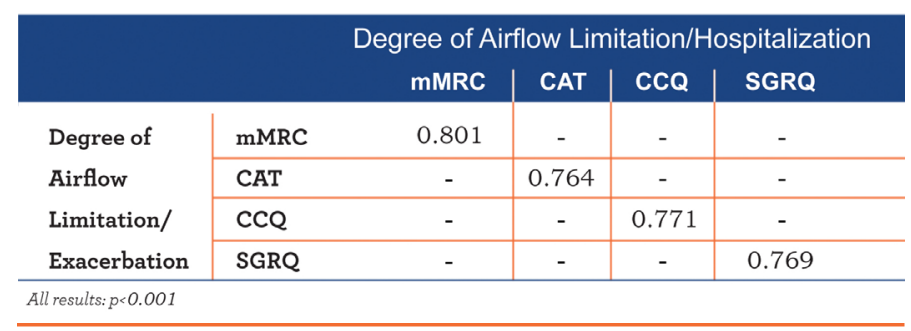

GOLD A patients had higher (=worse) HADS-A and HADS-D scores compared to CAT GOLD A and SGRQ GOLD A patients.

\section{The Impact of Exacerbation Risk Assessment on Frequency Distribution}

Table 4 shows that there is substantial agreement between the classifications using the exacerbation history and hospitalization history as risk assessment.

\section{The Impact of Exacerbation Risk Assessment on Clinical Characteristics}

In general, the impact of choice of symptom cut-point measure on demographic and clinical characteristics was similar for both exacerbation risk assessment groups (Figure 2, e-Table 1a and e-Table 1b). Health status, physical mobility, symptoms of anxiety and depression and self-reported comorbidities were comparable between both exacerbation risk assessment groups (Figure 2).

\section{Discussion}

\section{Key Findings}

This is the first study investigating the impact of the 4 GOLD-recommended symptom measures (mMRC, CAT, CCQ and SGRQ) and the 2 measures for exacerbation risk (exacerbation and hospitalization history) on the frequency distribution of GOLD groups $A$ to $D$, and their clinical characteristics in COPD patients. It shows that the choice of symptom measure influences the frequency distribution of the new GOLD groups more than the measures for exacerbation risk. Moreover, health status and psychological symptoms differ between different outcome measures used to identify high and low symptom patients, in particular in GOLD groups A and B. Thus, our hypothesis that the symptom measures impact the GOLD distribution as well as the clinical characteristics of the GOLD groups is partly confirmed.

\section{The Impact of Symptom Measure on Frequency Distribution}

The distribution of patients between GOLD groups $\mathrm{A} / \mathrm{C}$ or $\mathrm{B} / \mathrm{D}$ was dependent on the choice of symptom measure. As suggested before, ${ }^{6}$ this is not surprising since CAT, CCQ and SGRQ cover a broad variety of symptoms and have been developed differently compared to mMRC. ${ }^{18,19}$ The current study extends previous reports ${ }^{6,22}$ and shows that the mMRC cutpoint of $\geq 2$ gives an overrepresentation of patients classified in groups $A$ and $C$ compared with cut-points of the CAT, CCQ and SGRQ. In addition, previous studies only included primary and secondary care patients, ${ }^{22,23}$ while the majority of patients in the current analyses were recruited in tertiary care. As suggested before, ${ }^{23}$ the distribution of patients across GOLD groups seems to differ by sample population. The results also show that the impact of the choice of symptom measure is most pronounced in the low risk groups GOLD A/B. Probably, the impact of severe airflow limitation or exacerbations/hospitalizations on health status is more pronounced in the high-risk groups GOLD C/D, compared to the low-risk groups GOLD A/B, which may overwhelm the impact of choice of symptom measure in the high-risk groups. The current study found a similar degree of agreement between $\mathrm{mMRC}$ and CAT compared to previous studies $6,9,22$ and showed even a better agreement between $\mathrm{MMRC}-\mathrm{CCQ}$ and CAT-CCQ with best agreement between CCQ-SGRQ. However, the current study extends previous findings ${ }^{24}$ showing a similarly strong relationship between CAT and CCQ $(\mathrm{r}=0.771, \mathrm{p}<0.001)$ and the best relationship between CCQ and SGRQ ( $r=0.853, \mathrm{p}<0.001)$ (e-Figure 1).

Patients with a CAT score $\geq 10$ points experience a negative impact of their disease on their daily lives. ${ }^{25}$ Jones and colleagues ${ }^{6}$ showed that the classification of low symptom patients were approximately equivalent using the cut-points of mMRC grade $\geq 1$ and CAT score $\geq 10$. Other studies suggest a CAT cut-point of 22 points $^{23}$ or 13 points ${ }^{26}$ to determine low symptom groups which correspond with an $\mathrm{mMRC}$ cut-point of 2 or more. However, the choice of an adequate cutpoint remains debatable: the updated GOLD 2014 guidelines suggest a cut-point for the CCQ between 1.0-1.5 points ${ }^{9}$ while the current study suggests a CCQ cut-point of $\geq 0.6$ points and an mMRC grade of $\geq 1$ matching with a CAT cut-point of $\geq 10$ points 
to reach the best agreement (e-Figure 2 and e-Figure 3). The classification is important since treatment is recommended according to the classification of the disease described in the GOLD guidelines. Although, the CAT and CCQ are both useful tools to assess patients' experience of COPD, ${ }^{24}$ it has been suggested to be challenging using both tools in clinical practice. ${ }^{27}$ Kim and colleagues ${ }^{22}$ suggested using the worse score on CAT or mMRC to allocate patients to GOLD groups $\mathrm{A} / \mathrm{C}$ or $\mathrm{B} / \mathrm{D}$, like the procedure for exacerbation risk assessment. However, if this procedure is applied in the current study, only $4.8 \%$ of all patients are classified in GOLD groups A/C of which most of them are classified in the low risk group $A$. Therefore, this procedure probably gives an underestimation of low symptom patients (GOLD A/C).

\section{The Impact of Symptom Measure on Clinical Characteristics}

Furthermore, the current study shows that patients classified as GOLD group A/C using mMRC reported a worse health status as compared to CAT or CCQ assessed patients. This supports and extends previous findings. ${ }^{6}$ Interestingly, in mMRC GOLD B, CCQ GOLD $B$ and SGRQ GOLD B groups, patients reported a worse health status compared with CAT GOLD B patients. Furthermore, mMRC GOLD A patients reported higher HADS-A and HADS-D scores compared to CAT GOLD A and SGRQ GOLD A patients. Previously, dyspnea and CAT scores have been associated with symptoms of anxiety and depression. ${ }^{28-30}$ Since mMRC GOLD A patients reported worse health status scores (Figure 2, e-Table $1 \mathrm{a}$ and e-Table $1 \mathrm{~b}$ ), it is reasonable that those patients also report higher HADS scores.

The current study identified significantly more selfreported comorbidities in $\mathrm{MMRC}$ GOLD B and SGRQ GOLD B/C compared to mMRC GOLD A, C and D and SGRQ A or D patients, respectively, while there were no differences in self-reported comorbidities between the GOLD groups when using the alternative GOLD-recommended symptom measures. Although previous studies also showed the highest prevalence of comorbidities in GOLD B, ${ }^{31,32}$ the present results once again emphasize the importance of the choice of symptom measure. In addition, these studies only used the mMRC to categorize symptoms ${ }^{31,32}$ while the current study considered all various scenarios.

Finally, the choice of risk assessment did not impact the frequency distribution or the clinical characteristics which is in line with a recently published report ${ }^{23}$ suggesting a $4.2 \%$ shift from low risk patients to high risk patients, independent of the symptom measure used. While the authors concluded that the meaning was clinically uncertain, ${ }^{23}$ the present study indicates that both measures for risk assessment are comparable.

\section{Limitations}

There are a number of aspects that need to be taken into consideration regarding the current study. The proportion of patients from primary (11.6\%), secondary (17.9\%) and tertiary (70.5\%) care is not equally distributed, which may limit the external validity of the current findings. Furthermore, the current findings need to be interpreted in the light of the number of comparisons that were made in the present study. ${ }^{33}$ Nonetheless, multiple findings in the same direction, rather than a single statistically significant result, suggest that these are not due to chance alone. Future studies are necessary to further assess the impact of the use of mMRC, CAT, CCQ and SGRQ on prognosis in all groups and to provide recommendations for disease management.

\section{Conclusion}

In contrast to the possibilities to assess future risk, the 4 possible symptom measures have an impact upon the distribution of patients between the new GOLD groups. This is especially seen in the low-risk GOLD groups $A$ and $B$, in terms of impact on health status and psychological symptoms. Health care professionals should be aware that patients differ in terms of health status and symptoms of anxiety and depression based on the symptom measure used.

\section{Acknowledgements}

None.

\section{Declaration of Interest}

SW, DES, MAS, DJAJ, JWMM, MvdA and FMEF have nothing to disclose. TvdM developed the CCQ and holds the copyrights. PWJ did not receive any payment or services from a third party for any aspect of the submitted work, but reports grants and personal fees from GSK, personal fees from Novartis, Almirall, Pearl and Jannsen and his university received consulting fees for work that he performed for Novartis (outside the submitted work). EFMW did not receive any payment or services from a third party for any aspect of the submitted work, but reports grants and/or personal fees from Nycomed, AstraZeneca, GSK and Novartis (outside the submitted work). 


\section{References}

1. Rabe KF, Hurd S, Anzueto A, et al. Global strategy for the diagnosis, management, and prevention of chronic obstructive pulmonary disease: GOLD executive summary. Am J Respir Crit Care Med. 2007;176(6):532-555. doi: http://dx.doi.org/10.1164/rccm.200703-456SO

2. Vanfleteren LE, Spruit MA, Groenen M, et al. Clusters of comorbidities based on validated objective measurements and systemic inflammation in patients with chronic obstructive pulmonary disease. Am J Respir Crit Care Med. 2013;187(7):728735. doi: http://dx.doi.org/10.1164/rccm.201209-1665OC

3. Spruit MA, Polkey MI, Celli B, et al. Predicting outcomes from 6-minute walk distance in chronic obstructive pulmonary disease. J Am Med Dir Assoc. 2012;13(3):291-297. doi: http://dx.doi.org/10.1016/j.jamda.2011.06.009

4. Graat-Verboom L, van den Borne BE, Smeenk FW, Spruit MA, Wouters EF. Osteoporosis in COPD outpatients based on bone mineral density and vertebral fractures. $J$ Bone Miner Res. 2011;26(3):561-568.doi: http://dx.doi.org/10.1002/jbmr.257

5. Vestbo J, Hurd SS, Agusti AG, et al. Global strategy for the diagnosis, management, and prevention of chronic obstructive pulmonary disease: GOLD executive summary. Am J Respir Crit Care Med. 2013;187(4):347-365. doi: http://dx.doi.org/10.1164/rccm.201204-0596PP

6. Jones P, Adamek L, Nadeau G, Banik N. Comparisons of health status scores with MRC grades in COPD: implications for the GOLD 2011 classification. Eur Respir J. 2013;42:647-654. doi: http://dx.doi.org/10.1183/09031936.00125612

7. Han MLK, Muellerova H, Curran-Everett D, et al. GOLD 2011 disease severity classification in COPDGene: a prospective cohort study. Lancet Respir Med. 2012;1(1):43-50. doi:

http://dx.doi.org/10.1016/S2213-2600(12)70044-9

8. Agusti A, Hurd S, Jones P, et al. FAQs about the GOLD 2011 assessment proposal of COPD: a comparative analysis of four different cohorts. Eur Respir J. 2013;42(5)1391-1401. doi: http://dx.doi.org/10.1183/09031936.00036513

9. Casanova C, Marin JM, Martinez-Gonzalez C, et al. New GOLD classification: longitudinal data on group assignment. Respir Res. 2014;15:3. doi: http://dx.doi.org/10.1186/1465-9921-15-3

10. Global Initiative for Chronic Obstructive Lung Disease (GOLD). Global strategy for the diagnosis, management and prevention of COPD. http://www.goldcopd.org/ . Published 2011. Updated: Jan 2014. Date accessed: March 2014.

11. Metsemakers JF, Höppener P, Knottnerus JA, Kocken RJ, Limonard CB. Computerized health information in the Netherlands: A registration network of family practices. $\mathrm{Br} J$ Gen Pract. 1992;42(356):102-106.

12. Spruit MA, Pennings HJ, Janssen PP, et al. Extra-pulmonary features in COPD patients entering rehabilitation after stratification for MRC dyspnea grade. Respir Med. 2007;101(12):2454-2463.doi:

http://dx.doi.org/10.1016/j.rmed.2007.07.003
13. Mahler DA, Wells CK. Evaluation of clinical methods for rating dyspnea. Chest. 1988;93(3):580-586. doi:

http://dx.doi.org/10.1378/chest.93.3.580

14. Mesquita R, Janssen DJ, Wouters EF, Schols JM, Pitta F, Spruit MA. Within-day test-retest reliability of the timed "Up \& Go" test in patients with advanced chronic organ failure. Arch Phys Med Rehabil. 2013;94:2131-2138. doi: http://dx.doi.org/10.1016/j.apmr.2013.03.024

15. Charlson ME, Pompei P, Ales KL, MacKenzie CR. A new method of classifying prognostic comorbidity in longitudinal studies: development and validation. J Chronic Dis. 1987;40(5):373-383. doi: http://dx.doi.org/10.1016/0021-9681(87)90171-8

16. Zigmond AS, Snaith RP. The hospital anxiety and depression scale. Acta Psychiatr Scand. 1983;67(6):361-370. doi: http://dx.doi.org/10.1111/j.1600-0447.1983.tb09716.x

17. Puhan MA, Frey M, Buchi S, Schunemann HJ. The minimal important difference of the hospital anxiety and depression scale in patients with chronic obstructive pulmonary disease. Health Qual Life Outcomes. 2008;6:46. doi: http://dx.doi. org/10.1186/1477-7525-6-46

18. Jones PW, Harding G, Berry P, Wiklund I, Chen WH, Kline Leidy N. Development and first validation of the COPD Assessment Test. Eur Respir J. 2009;34(3):648-654. doi: http://dx.doi.org/10.1183/09031936.00102509

19. van der Molen T, Willemse BW, Schokker S, ten Hacken NH, Postma DS, Juniper EF. Development, validity and responsiveness of the Clinical COPD Questionnaire. Health Qual Life Outcomes. 2003;1:13. doi: http://dx.doi.org/10.1186/1477-7525-1-13

20. Jones PW, Quirk FH, Baveystock CM. The St. George's Respiratory Questionnaire. Respir Med. 1991;85 Suppl B:25-31.

21. Landis JR, Koch GG. The measurement of observer agreement for categorical data. Biometrics. 1997;33:159-174. doi: http://dx.doi.org/10.2307/2529310

22. Kim S, Oh J, Kim YI, et al. Differences in classification of COPD group using COPD assessment test (CAT) or modified Medical Research Council (mMRC) dyspnea scores: a cross-sectional analyses. BMC Pulm Med. 2013;13:35. doi: http://dx.doi.org/10.1186/1471-2466-13-35

23. Jones PW, Nadeau G, Small M, Adamek L. Characteristics of a COPD population categorised using the GOLD framework by health status and exacerbations. Respir Med. 2014;108(1):129135. doi: http://dx.doi.org/10.1016/j.rmed.2013.08.015

24. Tsiligianni IG, van der Molen T, Moraitaki D, et al. Assessing health status in COPD. A head-to-head comparison between the COPD assessment test (CAT) and the clinical COPD questionnaire (CCQ). BMC Pulm Med. 2012;12:20. doi: http://dx.doi.org/10.1186/1471-2466-12-20

25. Jones PW, Tabberer M, Chen WH. Creating scenarios of the impact of COPD and their relationship to COPD Assessment Test (CAT) scores. BMC Pulm Med. 2011;11:42. doi: http://dx.doi.org/10.1186/1471-2466-11-42 
26. Pillai AP, Turner AM, Stockley RA. Global Initiative for Chronic Obstructive Lung Disease 2011 symptom/risk assessment in alpha1-antitrypsin deficiency. Chest. 2013;144(4):1152-1162. doi: http://dx.doi.org/10.1378/chest.13-0161

27. Langhammer A, Jones R. Usefulness of the COPD assessment test (CAT) in primary care. Prim Care Respir J. 2013;22:8-9. doi: http://dx.doi.org/10.4104/pcrj.2013.00022

28. Janssen DJ, Spruit MA, Leue C, et al. Symptoms of anxiety and depression in COPD patients entering pulmonary rehabilitation. Chron Respir Dis. 2010;7(3):147-157. doi: http://dx.doi.org/10.1177/1479972310369285

29. Nagata K, Tomii K, Otsuka K, et al. Evaluation of the chronic obstructive pulmonary disease assessment test for measurement of health-related quality of life in patients with interstitial lung disease. Respirology. 2012;17(3):506-512. doi: http://dx.doi.org/10.1111/j.1440-1843.2012.02131.x

30. Hilmarsen CW, Wilke S, Engan $\mathrm{H}$, et al. Impact of symptoms of anxiety and depression on COPD Assessment Test (CAT) scores. Eur Respir J. 2014;43(3):898-900. doi: http://dx.doi.org/10.1183/09031936.00163913

31. Lange P, Marott JL, Vestbo J, et al. Prediction of the clinical course of chronic obstructive pulmonary disease, using the new GOLD classification: a study of the general population. Am J Respir Crit Care Med. 2012;186(10):975-981. doi: http://dx.doi.org/10.1164/rccm.201207-12990C

32. Agusti A, Edwards LD, Celli B, et al. Characteristics, stability and outcomes of the gold 2011 copd groups in the eclipse cohort. Eur Respir J. 2013. 42(3):636-646. doi: http://dx.doi.org/10.1183/09031936.00195212

33. Perneger TV. What's wrong with Bonferroni adjustments. BMJ. 1998; 316(7139):1236-1238. doi: http://dx.doi.org/10.1136/bmj.316.7139.1236 